\title{
LA APLICACIÓN DE TÉCNICAS BIOTECNOLOGÍAS EN EL MEJORAMIENTO DE CULTIVOS ORNAMENTALES
}

\section{APPLICATION OF BIOTECHNOLOGICAL TECHNIQUES IN ORNAMENTAL PLANT BREEDING}

\author{
Escandón, A. \\ Instituto de Floricultura, CIRN, INTA-Castelar. De los Reseros y Nicolás Repetto s/n. Hur- \\ lingham, Pcia. de Buenos Aires. Argentina.
}

E mail: aescandon@cnia.inta.gov.ar

Tradicionalmente se ha empleado el mejoramiento clásico para obtener variedades ornamentales exitosas que satisfagan las demandas de un mercado ávido de novedades, que busca nuevas características en cuanto a colores, formas, aromas, etc. Sin embargo, las tendencias actuales hacia la mejora ecológica de los cultivos y la necesidad de incorporar caracteres tales como resistencia a herbicidas, insectos, enfermedades, mayor vida en post cosecha, modificar la arquitectura de las flores y de las plantas, entre otras, ha conducido a la industria de la floricultura a adoptar las nuevas biotécnicas.

La aplicación de estas biotécnicas para el mejoramiento de ornamentales se constituye en una poderosa herramienta, alternativa y a la vez complementaria con los métodos de mejoramiento clásico. Los 30.000 millones de dólares anuales que mueve el negocio mundial de los cultivos ornamentales justifica largamente la aplicación de estas técnicas para un mercado exigente en calidad y en constante crecimiento.

Las técnicas biotecnológicas de aplicación para el mejoramiento en ornamentales son, el cultivo in vitro de tejidos, la transformación genética y los marcadores moleculares.

El aporte del cultivo de tejidos es por un lado, vía la micropropagación, la posibilidad de una producción homogénea y masiva y, por el otro, vía el cultivo de tejidos desdiferenciados y la mutagénesis in vitro, se constituye en una fuente de variabilidad genética de suma importancia.

Además de la micropropagación, la posibilidad de obtener plantas libres de virus por medio del cultivo de meristemas también ha sido explotada en ornamentales. Hace más de 50 años Morel y Martín informaron la regeneración de plantas de dalia libres de virus por escisión y cultivo

del domo meristemático de ápices de plantas infectadas. Este descubrimiento dio un gran impulso al cultivo de tipo intensivo en general. El cultivo de meristemas es uno de los métodos más eficaces para la eliminación de virus, más aún si se lo combina con termoterapia y/o métodos químicos; es de gran aplicación en el campo de los cultivos intensivos tanto ornamentales como hortícolas. Como la mayoría de los cultivos ornamentales se multiplican asexualmente, estas enfermedades virales suelen ser un problema importante. La elección errónea de un material, por error o desconocimiento, provocaría la diseminación de estas enfermedades, con las consecuentes pérdidas económicas. El control sistemático de las enfermedades virales en los cultivos intensivos es un área vacante a cubrir en la Argentina.

La transformación vegetal es otra de las estrategias que se ha aplicado exitosamente en el mejoramiento y se ha difundido en forma sostenida entre los principales cultivos ornamentales. Varios factores han contribuido a este importante desarrollo, entre los que se puede considerar un profundo conocimiento de la bioquímica de las plantas (sobre todo en lo que hace a la síntesis de pigmentos), un notable manejo del cultivo de tejidos en las especies de interés, el alto valor agregado que implica la aplicación de la técnica, además de las ventajas adicionales que se pueden lograr en la incorporación de un carácter determinado (por ejemplo: ahorro de insumos, incremento en el rendimiento, etc.).

Asimismo, y desde un punto de vista totalmente ligado el mercado, los organismos genéticamente modificados (OGMs) ornamentales, no generan el mismo tenor de controversias que provocan los OGMs ligados al consumo alimentario 
humano como los cereales y las oleaginosas. Esta estrategia de mejoramiento permite la incorporación de un rasgo deseado sobre un fondo genético seleccionado y la incorporación de genes de los más diversos orígenes (hongos, bacterias, animales y otros vegetales) que, debidamente adaptados para su expresión en plantas, aportan características con una muy baja probabilidad de que sean incorporadas en forma espontánea en el genotipo de interés. A través de esta técnica es posible el logro de plantas con nuevos diseños y colores o expresando resistencia a enfermedades (bacterianas, fúngicas y virósicas), insectos y herbicidas, así como la adaptación a ciertos estreses.

Agrobacterium rhizogenes y el gen rol $C$ de su plásmido $\mathrm{Ri}$ es una poderosísima y relativamente económica herramienta para aplicar en el mejoramiento de ornamentales. En efecto, la introducción de este gen en el genoma de algunas especies ornamentales ha permitido la obtención de plantas de menor tamaño, flores de menor diámetro y pétalos y hojas modificados, lo que implica una significativa modificación de la arquitectura de la planta. En clavel, por ejemplo, la incorporación de este transgén produjo una serie de modificaciones morfológicas muy ventajosas como ser disminución de la dominancia apical, mayor capacidad de enraizamiento, mejor incorporación de metabolitos y mayor producción de varas (se incrementó tres veces en relación al producto no transgénico). En términos prácticos, estas modificaciones implican una sensible mejora en el rendimiento del cul- tivo. Los marcadores moleculares como herramienta para la caracterización y diferenciación entre genotipos fueron rápidamente utilizados por genetistas y mejoradores de plantas. Su neutralidad con relación al proceso de selección, su poder de resolución, la celeridad con que se obtiene la información y la independencia de los estados fisiológicos del material en estudio y de la época del año, son algunas de las ventajas que ofrece esta herramienta. Esta técnica permite, a través del conocimiento de la diversidad genética de la que se dispone, diseñar nuevas estrategias para el mejoramiento esto es, preseleccionando individuos según su distancias genéticas para cruzamientos dirigidos. Asimismo, detectando las bandas asociadas a determinadas características es posible realizar una selección asistida por marcadores y de esa forma acortar los tiempos de selección. Otra aplicación de los marcadores moleculares es el desarrollo de las denominadas huellas digitales genéticas con las cuales se podrán efectuar diagnósticos de gran certeza en la identificación varietal ya sea las defensas de los derechos de obtentor, así como de los intereses de los productores. En suma, la aplicación de herramientas biotecnológicas en el mejoramiento y la producción de cultivos ornamentales estimulan el desarrollo de una industria que se caracteriza por su alto impacto social. En esta presentación se hará un resumen del estado del arte de la biotecnología aplicada a cultivos ornamentales y se efectuará una reseña de los trabajos efectuados en el área en el Instituto de Floricultura.

\section{INNOVACIÓN EN FLORICULTURA EN CHILE: ANÁLISIS Y SITUACIÓN ACTUAL}

\section{FLORICULTURAL INNOVATION IN CHILE: ANALYSIS AND PRESENT SITUATION}

\section{Samarotto, M. \\ Coordinadora Programa Flores FIA. Loreley 1582, La Reina Santiago, Chile. \\ E-mail: msamarot@fia.gob.cl}

La floricultura nacional, desde sus inicios, se caracterizó por desarrollarse fundamentalmente en la zona central del país, entre la IV y la
Región Metropolitana, siendo la mayor región productora la $\mathrm{V}$, con la mayor superficie explotada en el país (cerca del 56\%), seguida por la Región 